\title{
Webs of activity in online course design and teaching
}

\author{
Lisa Peruski ${ }^{1} \&$ Punya Mishra ${ }^{2}$ * \\ ${ }^{1}$ Independent Scholar; ${ }^{2}$ Michigan State University, USA
}

\begin{abstract}
In this study, we followed three faculty members' experiences with designing and teaching online courses for the first time. In order to complete the activity, the faculty members had to work collaboratively with others across the university. Activity theory provided a framework within which to study faculty members' collaborative activities with members of different activity systems that had different goals, tools, divisions of labor and accountabilities. In concordance with activity theory, such differences led to contradictions, disturbances, and transformations in thinking and work activities. The results of the study have implications for individuals and systems undertaking technology integration in teaching.
\end{abstract}

\section{Introduction}

Course planning and teaching in higher education involves balancing multiple objectives. Through years of experience in face-to-face teaching, faculty members have generated a great deal of knowledge and skill, which is often characterized by automatic routines and tacit knowledge. The advent of the web and the growing online education industry is transforming this context. It requires new course design procedures to represent and teach content in new contexts. It requires the use of new tools, as well as the creation and transformation of artifacts. It also poses new problems that require new kinds of support and collaboration since faculty members may lack the technical ability to create their own online classes.

The activity of designing an online course is situated within a larger web of institutional, individual and technological contexts that may be different from those required to design and teach face-to-face courses. These new stakeholders may hold different goals, intentions, motivations and tools, as well as different rules (both implicit and explicit) for how they typically complete certain tasks. According to Bruce (1993), change often reflects situation-specific compromises between the old

\footnotetext{
*Corresponding author. 509A Erickson Hall, East Lansing, MI 48824-1034, USA.
}

Email: punya@msu.edu 
and the new ways of doing things. The participants interpret and then re-create the activity as they adapt it to fit with institutional and physical constraints, and with their own goals and practices. One of the goals of this study was developing a better understanding of this process of negotiation and interpretation. We also wanted to understand whether engaging in the new activity changed participants' thinking about larger issues of course design, teaching and learning, such as content representation, the role of teachers and the needs and requirements of students. Furthermore, we wanted to know whether the institution of new, collaborative work activities would change work processes and systems in any way.

Much of the existing research on online teaching focuses on issues such as how the course is implemented, the nature of the interaction between faculty and students and evaluation of learner outcomes (Bolanger \& Jordan, 2000; Mehrotra et al., 2001; Williams, et al., 1999). Specifically, a lot of the research (particularly in the area of computer mediated communication) tends to focus on particular technologies, such as different kinds of discussion or chat software, and how these are instantiated within an online class. Less emphasis has been given to the experiences of faculty members working collaboratively with others to develop and teach online courses and whether these activities change their thinking about larger issues of teaching, learning and technology. Consequently, we have little knowledge of how the interactions between various stakeholders may lead to changes in work processes and thinking across groups and individuals.

The approach to understanding phenomena in this study was inspired by activity theory, particularly the work of Engeström (1999, 2000a, 2000b). When looking at participants' learning and change processes in organizational settings, Engeström based his analysis on contradictions that occur within and between surrounding activities. Contradictions may occur between systems that have different goals, responsibilities and accountability, or there may be contradictions in how tools, objects and subjects are seen. Contradictions may also arise because individuals are concurrently members of multiple communities with different objects, tools and social relations. People must thus adjust roles, beliefs and actions to resolve conflicts that may exist within and between systems (Jonassen, 2000).

According to Hasu and Engeström (2000, p. 65), "contradictions manifest themselves in disturbances and breakdowns in work processes as well as workers' innovative attempts to solve them". Disturbances and breakdowns refer to disruptions in the normal functioning of things forcing individuals to adopt a more reflective or deliberative stance toward ongoing activity (Bodker \& Gronbaek, 1998; Winograd \& Flores, 1986). The importance of contradictions is that, although learning can be deliberate, contradictions can also be openings for learning, for transformations in thinking and work processes and for systemic change.

In this study, we followed three faculty members involved in designing and teaching their first online course. There were two main research questions:

1. What contradictions and disturbances emerge during the activities of designing and teaching an online class? 
2. Does participating in these activities transform the thinking of the participants or the systems on issues such as course design, teaching, learning, technology, and face-to-face teaching?

\section{The activity systems}

We begin by describing the multiple activity systems involved in helping the faculty members develop and teach their courses. These included the college, a faculty development class and the 'virtual university' (VU), a unit at the university level charged with administering online courses. Note that all names used in this study are pseudonyms.

\section{The college}

In 1999, a college within a large midwestern university created a new online master's degree program. In order to support faculty members in the creation of their online courses, the college offered a range of incentives and services to faculty members. These included a $\$ 10,000$ stipend and faculty seminars. In addition, the college also created a faculty development course. The idea was that although most faculty members had well-developed skills surrounding pedagogy, learning, and course design, they were less proficient technologically. The college asked two of its educational technology faculty members to create a course to teach their less technologically-proficient colleagues how to develop their own online courses. (One of the individuals who taught this course is the second author of this paper.)

\section{The faculty development class}

The faculty development class was a graduate course where students enrolled for credit towards their master's degree in educational technology. Faculty members, who were designing online courses that they would be teaching in the near future, volunteered to be a part of this class. Students enrolled in the course and worked collaboratively with faculty members to help them design online courses. The students often provided the technology expertise while the faculty members provided the course content. However, individuals often took on overlapping responsibilities as the course progressed. The faculty took on greater responsibility for decision making relating to technology while the students offered insights into issues related to course structure and content. (See Koehler et al., 2004, and Mishra \& Koehler, 2003 for more information on the dynamics of the faculty development class.) Two of the three faculty members in this study, Jim and Juliet enrolled in the class. They worked closely with the technology to develop a mock-up of their course website. The third faculty member, Mikala, did not take the faculty development course and instead used her stipend to form her own student advisory group. Subsequently, all three took their courses to the VU who then hosted them. 


\section{The virtual university}

The VU is an independent unit at the university level whose job it is to help faculty teach online. Individual faculty members are responsible for developing the content of the course while the VU staff (designers and programmers) develop the technology and host the courses on their servers. VU staff have developed a series of software modules (a discussion board, chat rooms, file uploading facilities, etc.) that can be integrated into different courses. The VU assign a producer to coordinate the VU personnel (designers/programmers) and the faculty member teaching the course. The producer integrated the content provided by the faculty member with the tools made available by the VU technical staff and assisted the instructors in creating a course design, an aesthetic and a navigational structure for the course (Koehler et al., 2004).

\section{Research method}

\section{Participants}

The three faculty members in our study (Jim, Juliet and Mikala) were all faculty members in different departments at the College of Education. All were preparing to teach online courses for the first time. Each had years of experience (approximately 10 years) in teaching face-to-face courses in a higher education setting. Though the three online courses designed by the faculty members differed in their content, they had certain similarities. All three were discussion-based and involved students working in small groups to complete course objectives. The other participants in our study included a producer from the virtual university and a graduate student who worked with Mikala.

\section{Data Sources}

We used a case study approach to follow the three faculty members as they designed and taught their first online courses. The range of data collected for analysis included: multiple interviews with the three faculty members and others who worked with the faculty members on the project; artefacts created by the course design groups; and direct observations during both the course development and teaching activities. In this paper, we will look primarily at the interview data, which we describe below.

We interviewed each faculty member three times: first, during the design process; then around halfway through their teaching; and finally, after the course ended. The first interview gathered professional and technical background, data on how the faculty members carried out the course design activity, their perceptions about it, what they learned and data regarding their interactions with others and with the technology during the activity. The second interview focused on the faculty member's experience teaching the online class, their interactions with others (e.g. online students, the VU producer, and the VU system, etc.), their interactions with the technology and the course content and what they had learned from their activities so far. The final interview was a reflection on their experience of designing and teaching 
the online course, their interactions with people, systems and technology during these activities and what they had learned.

We also interviewed the VU producer who had worked with both Jim and Juliet. The producer was interviewed four times. The VU producer who worked with Mikala declined to participate in this study. Therefore, we interviewed Mikala's student assistant who had worked closely with Mikala and the VU producer throughout the design and implementation phases of the course. All interviews were semi-structured, involving open-ended questions. The interviews were structured to capture the participants' points of view on their experience and to identify contradictions, disturbances and transformations in thinking.

\section{Data analysis}

We reviewed the transcribed interviews multiple times to get a holistic conception of the content, to find instances that related to our study questions and to uncover unanticipated side issues. Subsequently, we created a chart for each faculty member into which we plugged data summarised from interviews and from supporting data sources that related to our study questions. We also created a cross-case chart to look across faculty members. We used the charts to develop the case studies and the cross-case analysis with a focus on the contradictions, disturbances and transformations that occurred during the activities of creating and teaching an online class. Though we developed detailed cases studies of each individual, as well as a cross-case analysis, we report just on the cross-case analysis in this paper. (See Peruski, 2003, for a complete report.) This cross-case analysis highlights the contradictions and disturbances that arose as each of the faculty members created and taught their online courses. Following this, we discuss the transformations that occurred in the individuals and systems, as well as implications of the study.

\section{Results: contradictions and disturbances}

\section{$A$ new context for teaching}

All of the faculty members were experts in the course content and in designing and teaching face-to-face classes. The activity of designing and teaching face-to-face classes represents standard work activities for faculty members. Hasu and Engeström (2000) describe standard work actions as "procedural steps that follow the script of a disturbance-free 'normal' process. Disturbances are analyzed as deviations from this scripted procedure" (p. 65; italics in the original). We argue that the new context for teaching (online) represented a deviation from each faculty member's normal script (designing and teaching face-to-face classes). Designing a course for a new context led the faculty members to question their role as teachers.

The surprising thing was how it tested and questions my own confidence as a teacher and really what teaching is all about anyway. What are you really doing when you are teaching? What is the value of your contribution in the whole thing? I don't know. (Jim, interview, 18 December 2001) 
The faculty members also had fears about their ability to teach in the new context and two of them wondered if they would enjoy it as much as their face-to-face teaching. These revelations were significant given the fact that all three of the faculty members had had extensive experience in teaching face-to-face. They indicated that merely participating in designing and teaching in the new online context led them to rethink and re-evaluate issues that they had long since put to rest in the face-to-face context.

\section{The faculty development class and the VU}

According to the VU script, the faculty member was responsible for developing the content while the VU staff developed the technology including the visual interface and the navigational structure. Thus the VU model treated the technology as separate from the pedagogy. Furthermore, the VU used idiosyncratic technologies developed in-house, which were not compatible with standard commercial software. VU producers had little training in curriculum and instructional design. They were more used to creating online lecture courses as opposed to interactive courses such as the ones proposed by the faculty members.

Such divisions of labour made pragmatic sense for financial and scheduling reasons. Furthermore, not all faculty members were intrinsically interested in learning about technology, seeing it as a waste of time (Koehler et al., 2004). However, the divisions of labour, rules and idiosyncratic technology often limited the design options for faculty members. As a result, producers often made decisions that could have unintended pedagogical consequences. Most VU courses have a standardised look and do not reflect the unique visions and styles of the faculty members (Mishra \& Koehler, 2003).

The faculty development course, on the other hand, asked faculty members to develop their own courses in their own ways, and to take more control over these activities. This often led to conflict with the goals of VU. In the course, faculty members worked with graduate students to create a mock-up of the online course. The design teams were also introduced to a variety of technologies and design options not available from the VU. Faculty members designed unique courses that fit with their personal and pedagogical goals and styles. In contrast to this, courses designed by the VU had less creativity and usually replicated courses that came before. The instructors for the faculty development class hoped that their customisable approach would encourage the VU to update their technology by virtue of having knowledgeable faculty members make more demands on the $\mathrm{VU}$ to create unique courses. However, this contradiction between the VU and the faculty development course (uniformity versus individualization of design) led to disturbances between faculty members and VU producers.

Another source of contradiction concerned the kinds of tools used in the faculty development course and the manner in which they were conceptualised. The faculty development course introduced the design teams to Blackboard (a commercial course management system) for use in developing the mock-ups of their online course websites. However, Blackboard was only one instantiation of what an online course website could look like. Blackboard is a highly integrated environment that 
also comes with an extensive suite of additional tools for student tracking, creating assessments and so on. Unlike Blackboard, the VU system was not an integrated system and it had a limited set of widgets that could be mixed and matched based on the requirements of a course. Hence the VU system had a very different design approach than Blackboard. Moreover, some of the tools that were integrated within Blackboard were not available from the VU. Having used Blackboard in the faculty development course, the faculty members may have assumed that such tools and add-ons would be available on any online teaching platform and thus they based their vision of their course on the availability of these tools.

For instance, Jim asked the VU for a tool to keep track of which students were online and when they were there. Although the VU had no such tool, the VU producer developed one, but was prevented from using it by his superiors due to concerns about human subjects' clearance. In some fundamental sense, differing views of what tools should be available created this entire disturbance. Jim felt that as an instructor he had the right to know which students were online and when. That was one way to assess participation. The producer's responsibility was to help the faculty member achieve his goals and thus created a widget to do that. However, the VU management saw looming ethical and legal issues regarding student privacy and did not allow the tool to be used.

Aside from the differences in tools between the VU and the faculty development class, the faculty members also spent time learning about and experimenting with a variety of course designs. They learned how to integrate their desire for highly interactive, discussion-based and writing intensive courses into the online environment. In summary, the faculty members took over control for most of the course design, aesthetics and navigational structures, which was often something that the VU producer controlled. Therefore, when the faculty members took their courses to the VU, they upset the usual divisions of labour.

The problem is we're a very centralized programming and server administration unit that everything has to go through and because of that, I can't use one thing for one class and use another thing for another class. I have to use one thing for all of them so that does cause some problems. (VU producer, interview, 20 December 2001)

Jim and Juliet, who took the faculty development course, deviated from the VU script by creating their own mock-ups of their courses instead of leaving that job to the VU producer. Jim also brought along several of his design team members that he had worked with in the faculty development class to work with the VU producer. Thus, the deviations from the usual divisions of labour and course structures led to disturbances as explained by the VU producer.

(Jim) had two people working with him who had an idea of how they thought it should be and I always got the picture from them that they didn't trust, they didn't think that I knew what I was doing and Jim was more willing to trust them than he was to trust me. (VU producer, interview, 20 December 2001)

The VU producer also referred to the contradictions between the VU system and the faculty development class. 
Working with (Jim's) graduate assistants that had different ideas on how things should be done (was a problem). The design is one, they're used to working outside the VU system. There's a certain amount of tools that we use at VU and people who are outside VU [have] become accustomed to working within other systems and it was really hard to get them to see that we need to mould things into our system. (VU producer, interview, 20 December 2001)

These disturbances were also frustrating for Jim. He was convinced that the VU system needed to change, and that instead of relying on the VU he needed to become more adept with the technology to achieve his goals.

The technology piece was just an irritant and that was a constant. The VU technology seems antiquated and cumbersome. I think there are a number of areas where VU needs to be much more supportive to make this online thing go. (Jim, interview, 18 December 2001)

Like Jim, Juliet also took the faculty development class where she created a mock-up of her online course. Her course was also designed to be highly interactive and it was structured in a way that the VU producer found confusing. Although the producer suggested changes to Juliet's site, she was resistant to most of his suggestions. Thus, Juliet co-opted more of the control over the design activity than was typical in the VU script. As a result, several disturbances emerged between Juliet and her VU producer that could be traced to contradictions between the $\mathrm{VU}$ and the faculty development class. In Juliet's course, neither the graphic nor the navigational structures fit the VU producer's vision or the traditional VU philosophy about how online courses should be designed. However, since one of his responsibilities was to satisfy Juliet, he worked with her original design but faced many difficulties organising navigation through the site.

It wasn't the prettiest site (compared to) other courses that have a more streamlined design. There were graphics that didn't need to be there. There's a rule in design that if you can take it out of the design and everything still looks good then you don't need to have it in there. In (Juliet's) design, there's stuff that could get trimmed but it didn't. (VU producer, interview, 11 September 2001)

Although the producer had made minor changes to the course, the course structure was still unfamiliar to him, which led to additional disturbances.

I changed around a few things. I added icons. Building the course was very confusing to me and it's my fault. It was wonderful for the students because it was really easy for them to get places but the way that I structured it; it was an organizational nightmare. It's not linear...whereas (other courses are linear). (VU producer, interview, 11 September 2001)

Though the producer blamed himself for the problems, they could also be linked to the contradictions between the faculty development class and the VU. The VU producer also believed that his lack of knowledge of teaching methods and curriculum design were a problem.

(It's) that gap of, I know how to do Web stuff and you know how to teach so let's get together and pool both. (VU producer, interview, 25 July 2001)

In contrast to Jim and Juliet, Mikala did not take the faculty development class. She followed the usual VU script by developing her content and taking it to a VU 
producer who used the available technological tools to put the course online. Although Mikala was satisfied with the VU system, one disturbance arose, which we believe was linked to the usual script for divisions of labour between the producers and faculty members. Mikala's course was highly interactive with several different teams of students working together on case studies. The VU producer lacked experience with highly interactive courses, as well as training in pedagogy and curriculum design. Mikala lacked experience with online contexts and technology tools. Therefore, neither of them had thought ahead to provide a separate virtual space for the online teams to interact. The result was that Mikala became overwhelmed trying to monitor each team's interactions. This disturbance may have been avoided if Mikala had taken the faculty development class where issues like this were discussed. Since the VU producer was a technology expert with some design skills, but not instructional design skills, he also did not realise the need for separate group threads.

The above examples taken from the cross-case analysis show how contradictions between systems in the tools, divisions of labour and rules that govern activities, as well as deviations from the usual script can manifest themselves in disturbances within and between the participants. This occurred despite the fact that both the faculty development course and the VU were there to help the faculty members design and teach their courses. However, the contradictions and disturbances were not always bad. Sometimes they led to transformations, which are outlined below.

\section{Results: transformations}

\section{Transformations in face-to-face teaching}

What was most interesting was that after teaching online, the three faculty members experienced transformations in their thinking about face-to-face teaching. Both Jim and Juliet said that the experience of getting to know their online students through their writing was powerful and that this increased emphasis on writing was something they would consider when they taught face-to-face.

\footnotetext{
I was more in touch with the online students' levels of inquiry and that was a good feeling to see that develop and grow. I've seen them begin to check their assumptions and see evidence that they're doing that because more of it is in writing. That will have repercussions now in my face-to-face classes. I've come to believe in more frequent assignments ... It forces students to deal seriously with the material sooner and ... in an integrative and ongoing way and then it gives us feedback sooner about what they're struggling with, what they're getting and what they're not getting. (Jim, interview, 18 December 2001)
}

The faculty members also found that their online students were more accountable for their thinking about the content compared to face-to-face classes. As a result, they hoped to find ways to change their face-to-face teaching to get similar results.

My groups used Web Talk so I saw everything they did in terms of response to questions and how they were processing the cases. All of that was very accountable. It was all right there on the Web for me to look at ... I saw everything they were thinking. I don't see that in my face-to-face courses. I heard everybody's voice and I don't in face-to-face. (Juliet, interview, 26 September 2001) 


\section{Knowledge about technology}

Mikala and Juliet both experienced transformations related to the use of technology and their comfort level using it in their face-to-face classes. These transformations were important considering that neither Juliet nor Mikala initially had a desire to learn much about the technology.

I have this zone of comfort around technology that I need to know only what I need to know ... but, I can actually do a lot more on the computer than I've done before. How it really has affected my teaching is that I am using more technology in my face-to-face teaching. Technology has helped me a lot in terms of expanding the realm of teaching. (Mikala, interview, 7 December 2001)

All of the faculty members gained more knowledge about technology and were interested in incorporating technologies into their face-to-face teaching. Because Jim and Juliet took the faculty development class, they were exposed to a wide range of technologies, assessed their usefulness and used some of them in the development of their websites. With their design teams, they interacted around ideas such as the relationships between content, technology and pedagogy, which played out in a number of ways during the activity of designing their online classes. They learned about the affordances and constraints various technologies provided, as well as the impact of the technology on representations of content. Although Mikala's course design process differed from that of Jim and Juliet, the interview data indicated that she also thought extensively about the role of technology in communications and student learning.

\section{The VU producer}

The VU producer's thinking about online course design and graphic design was also transformed. The experience also piqued his interest in researching such matters in graduate school.

(Juliet's) course wasn't designed by a professional graphic designer but it brings up a whole question of can graphic designers design good interfaces. Propelling my interest in research is [the question of] why the design worked well for these people. (VU producer, interview, 11 September 2001)

This issue also spilled over into his thinking about how people learn in the online context:

I was under the impression before that the more graphically streamlined something was, the better people are gonna learn (because) they've got less choices to make on each screen. I learned from this that giving them many choices on one screen actually was easier for them. Some of the questions it brought up is why did these people learn so much better when there was (multiple choices)? It prompted me to learn more about interface design; why certain interfaces work better than others in certain situations. (VU producer, interview, 11 September 2001)

The VU producer also thought about finding new ways to communicate with faculty members during the design activity. 
I think I would make it clearer in the beginning that they were working through VU for a reason and that if it wasn't going to work with VU, than maybe we should explore some other options, such as Blackboard, that would maybe suit their needs and wants better. (VU producer, interview, 20 December 2001)

\section{The systems}

System level change is a more complex and time-consuming process, but there were indications that changes may occur in both the faculty development class and the VU system. For example, the instructor for the faculty development class noted that the results from this study encouraged him to think about ways to change the class to make the transition to the VU easier for faculty members.

The VU producer changed the VU system by creating a couple of innovations at the request of Jim and Juliet. The innovations became part of the VU system and available for other producers and faculty members to incorporate into other classes. In addition, the producer began having discussions with $\mathrm{VU}$ administrators regarding how they change pedagogy when it goes online. He also acknowledged that the VU administrators realized that their tools had become outdated. They were also looking at ways to change the system to keep up with increased demand for their services, as well as new types of courses such as the highly interactive ones that the three faculty members designed.

\section{Transformation of work activity}

The new online program led to the creation of new work processes that took place in collaborative activity across and within systems. For instance, the faculty development class transformed the online course design activity at this university by combining faculty development and student learning for the purposes of designing an online course. The model not only changed the department's work activities, but could also have led to changes in the VU system.

\section{Conclusions}

In this study, we used an activity theoretical framework to analyse three faculty members' experiences with designing and teaching online courses for the first time. Systemic contradictions emerged due to the different systems' goals, tools and divisions of labour. The systemic contradictions sometimes led to disturbances in individuals' work processes and ultimately to transformations in both individuals, work processes and in systems.

The results of this study have implications for individuals and systems undertaking technology integration in teaching. For example, the new online context forced the faculty members to face their anxieties about their ability to teach using technology. The activity also raised questions for faculty members about their own role and identity as teachers. The new context represented a disturbance to established practices that provided the opportunity to face previously tacit thinking about issues such as 
course design, teaching methods and philosophies on teaching and learning. Although these are teaching dilemmas that good teachers often grapple with, this study revealed that these issues often become automatic and scripted unless faced with a disturbance. The online context provided a valuable laboratory in which to re-visit these important issues. Thus, although teaching online is time-consuming and sometimes creates anxiety, it can be an important activity because it may foreground some critical pedagogical dilemmas that good teachers need to think about.

Teaching online also provided faculty members with new insights into their faceto-face teaching. Increased student participation online and greater visibility of students' work encouraged faculty members to re-think their face-to-face teaching. They also gained a better understanding of technology generally, as well as how to integrate it into their face-to-face classes.

There were also implications for individuals that may work with faculty members to develop online classes. For example, the VU producer's thinking was transformed in several ways due to contradictions such as differences in design orientation, background, divisions of labour and the technological tools available from the VU. The producer learned about new course design options and navigational structures; he created new technological innovations to satisfy faculty requests; he began to think about new ways to interact with faculty members in order to avoid disturbances in the future; and this experience was one of the driving forces behind his decision to enrol in a graduate program to research questions raised while working with these faculty members.

In terms of the systems involved in the study, the faculty development course was an important support provided by the college. Faculty members learned more about technology and took more control over the online course design process than was typical for most faculty members who worked with the VU system at this institution. In addition, the faculty development course provided a new model for faculty development that other institutions could benefit from.

One of the values of the faculty development course was that it was not specific to particular technologies. This was important because technology changes quickly. Opening up technological possibilities provided faculty members with more knowledge of technology, greater control over their own course designs, and it led to transformations in thinking and technological innovations. However, the faculty development model also raised questions about whether it was a good idea to have a course that, by design, opened up technological and design possibilities for faculty members as opposed to more narrowly constraining them to fit within the model already established by the VU. This faculty development model created some disturbances and frustrations for the participants that might have been avoided with a different model, or one that was more sensitive to the potential disturbances the class could create between faculty members and VU producers.

Since many institutions are currently seeking to support academics' transition to using new technologies, it is likely that they could use this data to anticipate some of the contradictions and disturbances that might arise for them, thereby benefiting both faculty members and their students. However, not all contradictions and disturbances 
can be anticipated. Additionally, this study showed that contradictions are not necessarily bad, since steps that individuals and organizations take to minimise them often lead to transformations in thinking, work processes and technological innovations, as well as to new contradictions and disturbances.

\section{Acknowledgements}

We would like to thank the editors and two anonymous reviewers for their feedback on a previous version of the manuscript. We would also like to thank all the participants of our study for generously sharing their time and experiences with us.

\section{References}

Bodker, S. \& Gronbach, K. (1998) Users and designers in mutual activity: an analysis of cooperative activities in systems design, in: Y. Engeström \& D. Middleton (Eds) Cognition and communication at work (Cambridge, Cambridge University Press), 130-158.

Bolanger, F. \& Jordan, D. (2000) Evaluation and implementation of distance learning: technologies, tools and techniques (Hershey, Idea Group Publishing).

Bruce, B. (1993) Innovation and social change, in: B. Bruce, J. Peyton \& T. Batson (Eds) Networkbased classrooms: promises and realities (Cambridge, Cambridge University Press), 9-32.

Engeström, Y. (1999) Activity theory and individual and social transformation, in: Y. Engeström, R. Miettinen \& R. Punamaki (Eds) Perspectives on activity theory (Cambridge, Cambridge University Press), 19-38.

Engeström, Y. (2000a) From individual action to collective activity and back: developmental work research as an interventionist methodology, in: P. Luff, J. Hindmarsh \& C. Heath (Eds) Workplace studies: recovering work practice and informing system design (Cambridge, Cambridge University Press), 150-166.

Engeström, Y. (2000b) Activity theory as a framework for analyzing and redesigning work, Ergonomics, 43(7), 960-974.

Hasu, M. \& Engeström, Y. (2000) Measurement in action: an activity-theoretical perspective on producer-user interaction, International fournal of Human-Computer Studies, 53, 61-89.

Jonassen, D. H. (2000) Revisiting activity theory as a framework for designing student-centered learning environments, in: D. Jonassen \& S. Land (Eds) Theoretical foundations of learning environments (Hillsdale, NJ, Lawrence Erlbaum Associates), 89-121.

Koehler, M., Mishra, P., Hershey, K. \& Peruski, L. (2004) With a little help from your students: a new model for faculty development and online course design, fournal of Technology and Teacher Education, 12(1), 25-55.

Mehrotra, C., Hallister, C. \& McGahey, L. (2001) Distance learning: principles for effective design, delivery and evaluation (London, Sage).

Mishra, P. \& Koehler, M. (2003) Not what but how: becoming design-wise about educational technology, in: Y. Zhao (Ed.) What should teachers know about technology: perspectives and practices (Greenwitch, Information Age Publishing), 99-121.

Peruski, L. (2003) Contradictions, disturbances, and transformations: an activity theoretical analysis of three faculty members' experience with designing and teaching online courses. Unpublished doctoral dissertation, Michigan State University, East Lansing, MI.

Williams, M. L., Paprock, K. \& Covington, B. (1999) Distance learning: the essential guide (Thousand Oaks, CA, Sage).

Winograd, T. \& Flores, F. (1986) Understanding computers and cognition: a new foundation for design (Norwood, NJ, Ablex). 